\title{
DISSERTATION ABSTRACTS
}

Backer, Paul Allen. Ph.D., University of California, Irvine, 2009. Shakespeare, Alchemy and Dao (Tao): The Inner Alchemical Theatre. UnM: AAT 3365814

Over the years Shakespeare has been analyzed employing a variety of different critical methodologies but the majority of these have been grounded in the Western critical tradition. There have been few critical analyses that have viewed Shakespeare from a non-Western perspective, even fewer from a Chinese philosophical perspective.

This analysis is a comparative, cross-cultural reading of Shakespeare from the perspective of Daoism (Taoism), the classical Chinese philosophy, religion and practice, and simultaneously employs historical analysis and critical theory. Historically, Shakespeare and Daoism are, as Hamlet says, "mighty opposites" (5.2.62).

The historical bridge between these two "mighty opposites" is alchemy, or jindan in Chinese. Alchemy was an interdisciplinary cultural discourse and physical practice in both the West and China for many centuries, and was particularly significant in both the Western early modern period and in Daoism.

Western and Daoist alchemy share many important elements in common: material practices, philosophy, cosmology, and a worldview that has been the subject of scholarly study under the heading of the "esoteric" and "esotericism." In Daoist terms, there is ganying or "resonance" between them. In Shakespeare's time, esotericism included the traditions known as mysticism, Hermeticism, the "occult philosophy," the Christian Kabbalah (Cabala), and Rosicrucianism, and the practices of astrology, magic and alchemy.

Alchemy has two related forms, outer or physical alchemy (waidan) employing external materials, and inner or spiritual alchemy (neidan) employing the body, spirit and soul of the alchemist. Both processes were a journey of transformation that took place within what was referred to as the "alchemical theatre." Their goal was a return to originary wholeness or dao, which was often paradoxically equated with primordial "chaos" or hundun.

The critical approach of this analysis employs the philosophy, cosmology and practices of Daoist inner alchemy or neidan in a reading of 
Shakespeare's Hamlet and King Lear as xiang or embodied metaphors of the inner alchemical journey.

This exploratory cross-cultural methodology contributes to the related fields of critical theory, performance theory, comparative literature and philosophy, hermeneutics and intercultural studies.

Barton, Loukas William. Ph.D., University of California, Davis, 2009. Early Food Production in China's Western Loess Plateau. UnM: AAT 3396834 .

There is little doubt that agriculture evolved independently in East Asia, but its timing, nature and context are subject to considerable debate. Explanations for the motivations behind both the earliest efforts at food production, and the subsequent intensification of it are problematic because we know little about the hunter-gatherers responsible for the earliest experiments, and because the timing and intensity of food production are difficult to identify archaeologically. This thesis describes an attempt to address these problems in China's western Loess Plateau, one of several places where food production appears early in the Holocene.

Recent excavations at the Dadiwan site in Gansu Province provide a near continuous record of human activity prior to the origin of agriculture, including a plausible connection between Terminal PleistoceneEarly Holocene hunter gatherers of the western Loess Plateau and those from the deserts north of the Yellow River. Stable isotope biochemistry of animal bone from Dadiwan documents a symbiotic mutualism between early Holocene microblade-making hunter-gatherers, their dogs, and a $\mathrm{C}_{4}$ plant, most likely broomcorn millet (Panicum miliaceum), by at least 7500 calBP. Archaeological data throughout the region point to short-term occupations, low population densities, a commitment to large-bodied wild mammals, and limited investments in crop management, plant processing and storage, all characteristic of low-level food production. By 7200 calBP this pattern disappears from the region.

Soon after 6500 calBP a fully intensive relationship between people, plants, dogs, and pigs appears in the western Loess Plateau. Stable isotope biochemistry from the bones of pigs, dogs, and people at Dadiwan illustrate the strength of this relationship, while archaeobotanical remains throughout the western Loess Plateau reveal commitments to the use of both broomcorn millet and foxtail millet (Setaria italica), but little else. This dependence on agricultural products corresponds to the dramatic population growth and demic expansion associated with the Yangshao Neolithic.

The transition to agriculture in the western Loess Plateau illustrates an evolutionary processes repeated in numerous different places at differ- 
ent times throughout arid northern China. The methods and hypotheses described here will help reveal the total pattern of agricultural origins in East Asia.

Beningson, Susan L. Ph.D., Columbia University, 2009.

Shaping Sacred Space: Studies in the Ritual Architecture and Artistic Programs of Early Buddhist Cave Temples and their Relation to Tombs in Fifth Century China. UnM: AAT 3386118

Han dynasty conceptions of the afterlife continued to be used in the shaping of mortuary culture in post-Han Gansu at Dingjiazha, Foyemiaowan, and Qijiawan and also in Buddhist sacred space in the earliest extant cave-temples at Dunhuang and Jintasi. By following the transmission of these plans we can begin to understand the complexity of the adaptation and assimilation of Buddhism in China.

Bradford, Rosalind E. Ph.D., University of Pennsylvania, 2009. The Guyuan Sarcophagus: Motifs and Explication. UnM: AAT 3363696.

The fragments of painted lacquer which had covered a coffin and also bronze pushou were discovered in a tomb in Leizumiao Village, Guyuan (originally Gaoping, later Yuanzhou?), Ningxia, in 1981. Due to the close resemblance to the lacquer remains in a number of recently excavated fifth century Northern Wei tombs in Datong (Pingcheng), Shanxi, and the undeveloped nature of Gaoping before the sixth century, it is proposed that the "Guyuan Sarcophagus" was made in Pingcheng and transported to be used in Gaoping. The sarcophagus is covered with an intricate array of motifs. Compared to the remains of the Zhou Dynasty (ca. 1045-221 в.C.E.), a great, and sudden, change can be seen in the artifacts of the Han Dynasty (202 в.C.E.-220 C.E.). Han sources and some earlier ones explain much of the decoration on the Guyuan Sarcophagus. If no sign of the development of a motif had previously appeared, it is presumed that it may have entered China via the Silk Route which was coming into use in the Han and continued to grow thenceforth.

Thus, a number of the motifs on the Guyuan Sarcophagus are traced to various regions of Eurasia. Included in these are vine scrolls from the Mediterranean, merlons from Iran, flaming shoulders and pearl roundels from Gandhara, human-headed birds from Egypt, and the Sogdian ceremony of Nowruz.

Other motifs were very much in the Chinese tradition including filial piety scenes, Xiwangmu and Dongwangfu, and the Heavenly River. These were combined on the same coffin with undeniably Buddhist figures and elements of the Sogdian Nowruz. All the above leads to 
speculation about the beliefs of the occupant and the possibility that the artist adhered more to traditional Han beliefs than did he. The occupant's ultimate posthumous fate remains unknown.

Cheng Wing Kin. Ph.D., Hong Kong University of Science and Technology (Hong Kong), 2009.

Critical Analysis of Mou Zong San's Understanding of the Philosophy of Lao Tzu with Reference to Concepts of "Zhi de Zhijue" and "Zhong Guan." UnM: AAT 3365905

Mr. Mou Zong San, one of the most important representatives of Contemporary New-Confucianism, tries to justify the fact that the human being has intellectual intuition (Zhi de Zhijue) in the Kantian sense through the tradition of Chinese philosophy. In my research project, I make it clear that with Mr. Mou Zong San's explanation and proof of the intellectual intuition of the Taoism of Lao Tzu is not the intellectual intuition in its original sense in Kant's philosophy. Moreover, I analyze that Mou's explanation and proof of the intellectual intuition of the Taoism of Lao Tzu will bring about certain theoretical problems, and pinpoint that the explanation is mainly built on his interpretation of Confucianism. The thesis also argues that Mou's interpretation of the Taoism of Lao Tzu as "metaphysics of vision-form," in contrast with the moral metaphysics of Confucianism, is inappropriate. Mou ignores the meaning of "Beingform" in the Taoism of Lao Tzu. As a result, he emphasizes too much the static state of vision through self-cultivation, which makes him overlook the initiative of Taoism.

Chu Xin. Ph.D., The Chinese University of Hong Kong (Hong Kong), 2010.

Study on Six Dynasties Jade. UnM: AAT 3446045.

Despite the historical significance of the Six Dynasties (220-589 C.E.) - a turbulent time between Han and Tang Dynasty—research on jades of the period remains a neglected overlooked topic. Short of systematic studies, our understanding of the functional change of jades from religious rituals to daily life and decoration is greatly lacking. The current thesis studies jades excavated from tombs and collected in museums, by identifying their dates, characteristics, and styles through comparison and stylistic analysis, and discusses the use of jades through three centuries of change.

The thesis begins with an introduction of important jade finds from 1949 to 2009, followed by three chapters (chapter 2-4) illustrating the jade culture of the Six Dynasties. Chapter 2 is a case study of a jade pendant set. This examination provides important implications on the stylistic 
origin and changes of jades in the Six Dynasties. Chapter 3 explores the cause of functional differences in jades produced and used by Chinese and non-Chinese people and their influences on Tang Dynasty jades. Chapter 4 discusses ingestion of jade as a religious quest for immortality under the impact of Daoism. The final chapter concludes the thesis with an investigation into the scarcity of jades from this period to define the significance of Six Dynasties jades in the broader history of Chinese jades.

Cosford, Jason Isaac. Ph.D., The University of Regina (Canada), 2009. A Contribution of Speleothem Isotope Geochemistry to the Interpretation of Paleoclimates in Eastern China. UnM: AAT NR65745.

Speleothems from Chinese caves provide precisely-dated, high-resolution archives of the history of the East Asian monsoon. Research in this field has grown rapidly in recent years and has greatly improved our understanding of the climatic variability in China and the linkages to the global climate system. This thesis contributes four stalagmite $\delta^{18} \mathrm{O}$ and $\delta^{13} \mathrm{C}$ records, dated by U-series methods, from Xiangshui Cave, Yaoba Don Cave, Lianhua Cave, and Jintanwan Cave.

Stalagmite $\mathrm{X}_{3}$ from Xiangshui Cave $\left(110^{\circ} 55^{\prime} \mathrm{E}, 25^{\circ} 15^{\prime} \mathrm{N}\right.$, elevation 380 m.), Guangxi Province and stalagmite YB 1 from Yaoba Don Cave ( $109^{\circ} 50^{\prime}$ E, $28^{\circ} 48^{\prime} \mathrm{N}$, elevation $420 \mathrm{~m}$.), Hunan Province, span a portion of the last glacial period $(\sim 51$ to $\sim 19 \mathrm{ka})$. Millennial-scale fluctuations recorded in these stalagmites correlate with Dansgaard-Oeschger events (2-13) and Heinrich events $\left(\mathrm{H}_{2}-\mathrm{H}_{5}\right)$, demonstrating a linkage between the Asian monsoon and atmospheric and oceanic conditions in the region of the North Atlantic.

Lianhua Cave ( $109^{\circ} 32^{\prime} 45^{\prime \prime} E, 29^{\circ} 29^{\prime} \mathrm{N}$, elevation $455 \mathrm{~m}$.), Hunan Province, yielded an aragonite stalagmite (A1) covering the Mid- to LateHolocene ( 6.5 ka to present). During this period, the $\delta^{18} \mathrm{O}$ record shows an overall weakening of the East Asian monsoon with several distinct millennial-to-decadal-scale events, including an abrupt and severe weakening of the summer monsoon around $\sim 3.3 \mathrm{ka}$ that marks the onset of Neoglacial conditions. The expressions of these events in other Holocene stalagmites from China suggest similar regional changes with some local differences. Spectral and wavelet analyses reveal common periodicities that occur at both solar and non-solar frequencies. Variations in the $\delta^{13}$ $C$ record of stalagmite Ai reflect climatic influence on biological and inorganic processes. Periods of intensified summer monsoonal circulation correspond to lower $\delta^{13} \mathrm{C}$ values in response to increased plant growth and microbial activity in the soil, higher drip rates, and diminished cave air ventilation. 
Stalagmite J1 from Jintanwan Cave $\left(109^{\circ} 32^{\prime} \mathrm{E}, 29^{\circ} 29^{\prime} \mathrm{N}\right.$, elevation 460 $\mathrm{m}$.), Hunan Province, spans the interval from $\sim 30$ to $\sim 11$ ka with a hiatus between $\sim 15$ to $\sim 12 \mathrm{ka}$. The East Asian summer monsoon weakened and then strengthened during the Last Glacial Maximum in response to changes in northern hemisphere summer insolation and weakened during Heinrich event $I$ in response to changing oceanic circulation. Although the deglacial monsoon history expressed in stalagmite J1 is incomplete because of the hiatus, the transition from the Younger Dryas to the Holocene at $\sim 11.5 \mathrm{ka}$ is represented. The $\delta^{18} \mathrm{O}$ and $\delta^{13} \mathrm{C}$ values of this stalagmite were measured using microdrill and laser ablation sampling techniques. Comparisons between the two techniques demonstrate that laser ablation can quickly reproduce the overall trends in the microdrill data, but the microdrill data can achieve higher spatial resolution and greater precision.

Crisler, Philip Lance. M.A., University of Colorado at Boulder, 2009. The Role of Odes Quotation in Early China: The Mawangdui "Wuxing" and the Shanghai Museum "Kongzi shilun" Manuscripts. UnM: AAT 1473628.

The poems comprising what is now known as the Classic of Odes have long been important material in the construction of texts in China. The Odes often function as primary sources upon which authors create arguments. This paper examines the usage of odes in two recently discovered manuscripts: the Wuxing from Mawangdui Tomb 3 and the Kongzi shilun from the Shanghai Museum corpus. The widespread use of the odes in both these manuscripts and other received texts demonstrate that odes were established cultural constructions as early as the late fourth century в.с.E. Conversely, the nature of the odes' inclusion in these manuscripts - their arrangement as well as the various commentaries on them-suggests that there were multiple collections of odes and the received version of the Odes is one of many groupings.

This study first analyzes the use of certain odes in the Mawangdui Wuxing, remarking briefly on the commentarial strategies employed by the text's author(s). Next, it examines the various odes in the Kongzi shilun, tabulating each instantiation of the odes and commenting on a few noteworthy examples.

Davis, Timothy M. Ph.D., Columbia University, 2008.

Potent Stone: Entombed Epigraphy and Memorial Culture in Early Medieval China. UnM: AAT 3317543.

The men and women of early medieval China were highly sensitive to the obligations they owed their dead. The various genres of pragmatic and 
commemorative epigraphy recovered from the tombs of this era provide insight into how living descendants imagined the relationship with their deceased ancestors. Pragmatic forms of entombed epigraphy-typified by burial plot purchase contracts, tomb-quelling writs, and grave inventories (specifically those inventories with attached letters to underworld authorities) - aim at protecting the deceased from malevolent spiritual forces and settling him or her within the social setting of the underworld. They also often seek to delimit the sacred space in which the dead were allowed to operate, and occasionally coerce the spirits into maintaining a proper distance from the living by threatening them with posthumous harm. Commemorative forms of entombed epigraphy, on the other hand, celebrate the moral development and meritorious achievements of the dead with the aim of preserving their name and legacy for posterity and, if fortunate, inscribing their accomplishments into the cultural memory of the larger community.

While many genres related to death and burial are discussed in this study, I have chosen to concentrate on the "entombed epitaph inscription" or muzhiming for the following reasons: First, excavations of medieval tombs have yielded several thousand entombed epitaph inscriptions in recent years. The sheer number of tomb-interred epitaphs discovered so far marks them as a significant cultural phenomenon and demands concentrated inquiry into their origins and development, their religious, social, and commemorative functions, and their literary and rhetorical features. And secondly, previous scholarship devoted to entombed epitaph inscriptions has tended to emphasize their inherent value as unaltered source material for studying the development of the Chinese script or for supplementing traditional accounts of political and institutional history to the neglect of their role in the memorial culture of early medieval China.

The first three chapters of this study are concerned with identifying the antecedents of entombed epitaph inscriptions and exploring their practical functions. Chapter one locates the origins of entombed epitaph inscriptions at the crossroads of two traditions: (1) the canonical inscription tradition of commemorative texts associated with ancestral sacrifice, including inscribed bronze vessels and commemorative stelae, and (2) the documents of the pragmatic, common mortuary practice that prevailed during the early medieval period as preserved in the archaeological record. Chapter two focuses on examples of subterranean epigraphy that had been inscribed upon the actual structural elements of the tomb and its role in securing a final resting place of a particular deceased individual. Chapter three concentrates on the conditions under which entombed epitaphs first appear. For example, they are regularly 
deployed in circumstances of exigent burial, such as in cases where war, unrest, or great distance necessitated temporary burial away from the lineage homelands (waizang), or when reburial was necessary because the tomb had been damaged or required relocation to more auspicious environs (gaizang).

Chapters four and five explore the role of entombed epitaph inscriptions in the memorial culture of early medieval China. Chapter four distinguishes between the historiographical mode of biography, as preserved in the dynastic histories, and the commemorative mode found in entombed epitaph inscriptions pointing out their different audiences and rhetorical strategies. Chapter five concentrates on the process by which the entombed epitaph inscription was elevated to an esteemed literary genre practiced by many of the most admired writers in the pre-modern literary tradition.

Epstein, Shari Ruei-hua. Ph.D., Stanford University, 2010.

Boundaries of the Dao: Hanshan Deqing's (1546-1623) Buddhist Commentary on the "Zhuangzi." UnM: AAT 3431382.

This dissertation explores an example of the intersection of religious traditions through a close reading of the Buddhist monk Hanshan Deqing's (1546-1623) commentary on the Daoist classic, the Zhuangzi. An examination of this unusual commentary provides insight into how Hanshan, a prominent leader of the influential late Ming Buddhist revival, challenged assumed notions about the relationship among the Three Teachings: Buddhism, Confucianism, and Daoism. By presenting a careful, line-by-line exegesis, Hanshan transforms the Daoist Zhuangzi into a Buddhist text. Through this act of interpretation, Hanshan both contested Buddhist notions of orthodoxy and established a new genre of Buddhist writings on the Chinese classics, a genre that continues to influence Buddhist thought, practice, and understanding today.

Hanshan's belief that Master Zhuang was a Bodhisattva appearing in China to pave the way for Buddhism meant that his assumptions about the text differed radically from most of the commentators who came before him. Hanshan insisted that the Zhuangzi must be read as a religious text, containing both esoteric and exoteric teachings. He believed that Master Zhuang himself embedded in the classic's second chapter a prophecy that in a future age readers would discover the hidden Buddhist message within the text. In order to "decode" this Buddhist message, Hanshan pays particular attention to the interrelationship among the literary, philosophical, and soteriological elements of the work. He argues that it is necessary to understand and appreciate three styles of language-described in the Zhuangzi as Lodging Language, Weighted 
Words, and Spillover Sayings - in order to recognize and follow Master Zhuang's philosophical argument. According to Hanshan, the literary and philosophical aspects of the Zhuangzi serve the ultimate purpose of helping readers in their spiritual practice

Green, Debra Kay. Ph.D., University of Illinois at Chicago, 2010. Geoarchaeology of Prehispanic Agricultural Landscapes in the Bais-Tanjay Basin Negros, Oriental. UnM: AAT 3417317.

At the time of European contact, the Philippine archipelago was populated by numerous socio-politically complex maritime trading polities linked into the South China Sea-Indian Ocean luxury goods trade and interacting through river-based trade for raw materials with smaller-scale interior swidden farming and foraging groups. While historic records and archaeological work have begun to illuminate dynamic aspects of sociopolitical structure and economy in the precolonial complex societies of the Philippines, agricultural strategies and human impacts on prehispanic landscapes are little studied and poorly understood. My research involves an interdisciplinary approach using archaeology, geoarchaeology, GIS, and ethnohistory to assess strategies of agricultural intensification and landscape transformation within the Bais-Tanjay River Valley of Negros, Oriental, in response to ecological, political, and social factors.

Harris, Eirik Lang, Ph.D., The University of Utah, 2009. Morality in Politics: Panacea or Poison? UnM: AAT 3368316

In the Western philosophic tradition, virtue theory has rarely been extended to the political realm. There is a long tradition that advocates the role of virtue in ethical theory, but the implications of this tradition for political theory have largely been neglected. However, in the Chinese tradition, we very early on see the use of virtue-based theories not only in ethics but in political thought as well. Indeed, one of the most sophisticated early Confucian philosophers, Xunzi (fl. 298-238 в.C.E.), believes that a virtue-based political theory is a natural extension of his virtue-based ethical theory. At the same time, a prominent anti-Confucian political philosopher, Han Feizi, was diametrically opposed to allowing virtue, or, indeed, any other moral quality, serve as the basis for political theory, arguing instead that a clear set of laws should serve as the fundamental basis. Therefore, this tradition offers us a very clear debate on the problems and promise of a virtue politics.

This debate is not only of historical interest, however. To the extent that contemporary philosophers interested in the possibility of extending virtue theory to the political realm take themselves to be prescribing 
for everyone, as opposed to simply for those within their own cultural background, they must be willing to take into account other traditions that have wrestled with similar issues. In early China we not only see a version of virtue politics, we also see a sophisticated debate about its viability. And, while Xunzi himself may not be capable of answering all of Han Feizi's objections, analyzing this debate affords us the opportunity to see how and where a particular conception of virtue politics succeeds and fails, providing contemporary philosophers not only with a set of problems that must be overcome but also with a promising way forward.

Ho, Denise Yuet-Shu. Ph.D., Harvard University, 2009.

Antiquity in Revolution: Cultural Relics in Twentieth-Century Shanghai. UnM: AAT 3388379.

In twentieth-century China, cultural relics came to symbolize the authenticity and legitimacy of the state. This dissertation studies how cultural relics, or wenwu, were defined from China's Republican period (19121949) through the People's Republic (1949-) into the present day. While China's imperial rulers used cultural relics to demonstrate legitimate succession, the paradox facing any new regime in the twentieth century was that its claim to political legitimacy was based on both revolution and historical continuity. Taking Shanghai as its case study, "Antiquity in Revolution" examines this political tension through the authentication, nationalization, and display of cultural relics. This history of the city's arts and monuments explores how such relics have produced and supported national narratives.

This dissertation draws upon the records of the Shanghai Bureau of Culture. Building upon the regulations and rhetoric from the Republican period, the People's Republic established institutions to control cultural relics and their interpretation. In addition to using antiquity to define New China, these institutions also designated revolutionary places, including the site of the First Communist Party Congress. The state's cultural bureaucracy also reached into the lives of local people, creating neighborhood exhibitions, defining cultural relics within temple spaces, and regulating art trade to nationalize private collections. Despite the state's claims to mastery over the past, however, the cultural institutions remained politically fraught; the questions of whether museum officials were to be red or expert, how the history of the revolution was told, and who should define and own cultural relics demonstrate that the Party was not the sole claimant on culture or its definition.

Until the Cultural Revolution antiquity and revolution managed to coexist. But Mao's "Smash the Four Olds" campaign rejected the past; 
and in this context cultural officials had to reframe "preservation" by representing it as a revolutionary act. The enduring resonance of cultural relics to Chinese identity is reaffirmed in the cultural nationalism of today's globalizing China. But the tension between antiquity and revolution persists as the People's Republic, founded in revolution, seeks to integrate itself into China's longer historical narrative by redefining legitimate succession in the interest of the present Chinese nation-state.

Hsu Ya-hwei. Ph.D., Yale University, 2010.

Reshaping Chinese Material Culture: The Revival of Antiquity in the Era of Print, 960-1279. UnM: AAT 3415338.

This dissertation investigates the transformation in material culture during the Song dynasty (960-1279 C.E.). It argues that the all-encompassing, metropolitan style of the Tang (618-907 C.E.) arts was replaced with a retrospective aesthetic that was inspired by bronzes of China's high antiquity. The antiquarian trend, first advocated by scholar-officials in the court, was a branch of their cultural enterprise. Its goal was to restore Chinese culture to its prime state of antiquity in response to the foreign, barbarian military challenges that threatened the Song Empire. As factional hostilities mounted in emperor Huizong's (r. 1101-1125) court, antiquities became one of the weapons by which Huizong and his high officials fought their opponents. This political conflict gave rise to antiquarianism in the mid eleventh century and fueled its later development, causing dramatic changes in ritual objects and fine porcelains in Huizong's court.

During the Southern Song (1127-1279), through the mediation of antiquarian catalogues, this cultural ideal spread beyond the court to wider audiences and had an immense impact on material culture. Illustrated with images of ancient bronzes and bronze inscriptions, catalogues by Northern Song antiquarians were epitomes of their scholarly accomplishments. After being put into print, they further assumed the role of the mass media, spreading images of antiquities in a variety of forms. In addition, the printed catalogues also served as a kind of pattern book, from which ancient forms could be chosen and reworked to create archaic-looking objects. The direction of influence, however, was not one way. As archaism permeated the material world, features of recreated archaic objects were fused into catalogues during later re-cutting and reprinting. Contextual analysis further suggests that the appropriation of ancient bronze forms in the Southern Song moved beyond a formal borrowing to codify serious intents of their owners and their reactions to the cultural tradition they chose to inherit. 
Huang Kuan-yun. Ph.D., The University of Chicago, 2010.

Warring States "Echoes" of the Past. UnM: AAT 3397253.

"Warring States 'Echoes' of the Past" is about the use of quotation in Chinese literature of the Warring States period (481-221 B.C.). By considering a small number of quotations whose contents parallel what now appear in the received versions of two canonical texts, the Odes and Documents, it is possible to develop a methodology for the study of quotations, their various attestations, and the discourses in which they are embedded.

The Introduction provides a survey of quotations in ancient texts and is followed by an explanation of the approach, which considers five important aspects of a quotation: source, identification, other attestations, local context, and "practice" vs. "theory." The rest of the study is made up of four case studies.

In Chapter One, the discussion focuses on the quotation of the "Shijiu" (The cuckoo) and the imagery of a cuckoo feeding its seven chicks described in that poem. In particular, the discussion considers how the quotation is interpreted by two texts from the Warring States, the "Wuxing" (Five activities) and "Ziyi" (Black robe). Given that both the "Wuxing" and "Ziyi" are extant in multiple versions, produced at different moments in time, it is possible to see how their discussions of a single poem have changed over time.

The second chapter takes up the inherited tradition associated with the Documents. It does this by considering the "Cheng zhi wen zhi" and its interpretation of two quotations from the "Jun Shi" (Lord Shi). The investigation makes an attempt to reconstruct the discourse behind the two quotations. In the second part of the chapter, this involves placing the "Cheng zhi wen zhi" passage in the context of legends about Wu Ding, the famous ruler of the Shang. In the first part of the chapter, the situation is more complex, for the analysis there shows that the "Cheng zhi wen zhi," in its interpretation of the "Jun Shi," was drawing on another source associated with the Documents, the "Shaogao" (The announcement of Shao). Not all references to inherited traditions in Warring States texts are marked explicitly as such. The connection can include such intertextual references as the incorporation of certain key terms; the attempt to flesh out a theme, an image, or an idea; the adaptation of the sequence in which different arguments are advanced; and the act of paraphrasing, imitating, or rewriting an inherited tradition. An investigation concerning these intertextual connections, or what I refer to as "allusions," is the subject of Chapter Three. Focusing on two closely related passages from the "Liude" (Six virtues) and "Wuxing" (Five activities), the analysis shows that the two texts consist of a type of wordplay which draws a semantic linkage between a monosyllabic 
word and a reduplicative binome based on their phonological identity or similarity. In both cases, it is possible to trace the reduplicative binome back to a poem now found in the received text of the Odes. Given that the two poems are themselves closely related-both concern King Wen and are placed immediately adjacent to each other in the received text of the Odes - they point to a common source, perhaps a body of teachings concerning King Wen or a shared set of vocabulary for discussing him, which served as the basis of the two poems, the "Liude," "Wuxing," and a "commentary" of the "Wuxing."

If the first three chapters illustrate the "practice" of the quotation of inherited words during the Warring States, then the final chapter turns to what one might refer to as the "theory" about inherited words, particularly, by focusing on the "Xing zi ming chu" (Nature arises from fate), one of the most important texts to have been discovered recently. The "Xing zi ming chu" is unlike all of the newly excavated texts considered in the previous three chapters in that it describes, rather than quotes from inherited tradition. This refers to an extensive discussion in that text on the Odes, the Documents, the rites, and music. Based on a comparison with all other comparable accounts in the literary record, the analysis shows that the "Xing zi ming chu" is part of a more extended discussion about instruction, human nature, ancient tradition, and the response of the mind to external things. In this way, the "Xing zi ming $c h u$ " was participating in a debate about inherited tradition, and it shared with several early accounts a similar vocabulary and certain rhetorical strategies, even if they ultimately employed these devices to stake completely different claims. It is only in the Xunzi that one finds an attempt to synthesize the various positions and offer a program for the study of inherited tradition. (Abstract shortened by UMI.)

Hudak, Catherine Agnes. Ph.D., Boston University, 2009.

The Virtue of Humble Authority in Saint Thomas Aquinas and Master Zhu $X i$. UnM: AAT 3357656 .

Regardless of whether a person is a ruler, subject, or citizen, she will indubitably confront two great questions raised by authority: how should it be wielded? And: how should it be limited? In The Virtue of Humble Authority in Saint Thomas Aquinas and Master Zhu Xi, I argue that both issues are equally important, and that the answer to each involves the other.

This dissertation explores what an authority grounded in sacred order might look like, from the viewpoints of the European Catholic Thomas Aquinas (c. 1225-1273 C.E.), and the Chinese Neo-Confucian Zhu Xi (1130-1200 C.E.). These two figures, immensely influential in their respective traditions, were chosen in accordance with the conviction that 
any responsible discourse on authority must consider different cultural perspectives. Additionally, the systematic, idealistic approach common to both provides all the elements necessary for a comprehensive answer to the two questions above: the exploration of a sacred order inhabited rather than made by human beings; the presentation of human beings as intelligent agents with moral potential rooted in this sacred order; the description of how human beings develop their moral potential in human and cosmic community; the examination of authority properly exercised; and the investigation of the proper limits of authority. These components are presented in support of the main thesis: the proper exercise and limitation of authority requires a particular virtue, hitherto latent in both scholars' work. This virtue, humble authority, is described in the conclusion as properly grounded in the sacred order, and fully cognizant, in theory and in practice, of the parameters of human nature and the responsibilities attendant upon the human role.

As this project aims to provide an inclusive solution to a wide-ranging problem, it relies upon the insights of several academic disciplines. This approach is beneficial because it incorporates the invaluable insights of the social sciences, while taking the step of investing them with sacred meaning, thus answering the question of why one should cultivate the virtue of humble authority. Moreover, this method also introduces and addresses the religious concern for the flourishing of humankind and the world.

Kim Nam C. Ph.D., University of Illinois at Chicago, 2010.

The Underpinnings of Sociopolitical Complexity and Civilization in the Red River Valley of Vietnam. UnM: AAT 3446083.

This study is focused on the underpinnings of Vietnamese civilization in northern Vietnam's Red River Valley. Data were collected and analyzed through fieldwork excavations, laboratory analysis, and secondary research. The research examined the proto-urban site of Co Loa near modern-day Hanoi, believed to be the first capital of Vietnamese civilization. Though the site's monumental fortifications were purportedly constructed by an indigenously Vietnamese kingdom during the third century в.C.E., this semi-historical claim is based on a mix of oral traditions, legend, and myth. Compounding the situation are extant Chinese Imperial Han textual records which suggest that, prior to Han colonization of Vietnam during the first centuries B.C.E. and c.E., the Red River Delta area lacked social and political sophistication, being inhabited by local and indigenous "barbarians." Accordingly, the chronological reconstruction of the site's history provides critical new data for Vietnamese prehistory. 
Field investigations at Co Loa secured stratigraphic, construction, cultural, and chronological data from a portion of its massive system of earthen rampart enclosures. The findings reveal that a local, indigenous, state-level polity emerged in the area during the third century B.C.E., well before Han colonization. While far from proving the validity of Vietnamese oral accounts, the findings lend some support to the annals. In addition, the field research also revealed smaller fortification features buried beneath the rampart, a set of features belonging to a culturally distinct and smaller-scale society. These are the earliest fortification features to have been archaeologically detected within Vietnam, and the discovery hints at the possibility that pre-state communities in the area were engaging in periodic outbreaks of violence and warfare prior to political consolidation and state emergence.

The combination of data and analysis clearly suggests that the emergence of state-level, sociopolitical complexity was the result of a number of important factors, with coercion and warfare playing prominent roles. Accordingly, while contributing to early Vietnamese history, this study of the Co Loa case thus also holds vital significance for ongoing development of anthropological theories around social evolution and ancient state formation.

Klein, Esther Sunkyung. Ph.D., Princeton University, 2010. The History of A Historian: Perspectives on the Authorial Roles of Sima Qian. UnM: AAT 3414152.

In the first century в.с.E., Sima Qian compiled the Shiji, a history of China from mythological beginnings to his own day. Soon after, readers of the Shiji began producing both continuations and extensive comments. This dissertation examines the changing ways in which pre-modern Chinese readers understood authorship through an analysis of their perspectives on Sima Qian. I argue that we cannot know the "real" Sima Qian: the tragic authorial figure of Sima Qian is a construction by later readers. I trace the development of this authorial construction from the Han through Song dynasties, examining readers' comments within their historical contexts. The dissertation has three parts. The first outlines Sima Qian's fortunes in the textual world of traditional China, exploring how his authorial role was seen in relation to the Classics and to historical texts (in chapter 1 ), as well as to literary theory and composition (in chapter 2). Chapter 3 discusses formal aspects of the Shiji and how they were considered an aspect of Sima Qian's creative authorship.

The second part juxtaposes two competing interpretations of the Shiji. Chapters 4 and 5 analyze how Sima Qian's personal tragedy was thought to relate to his work on the Shiji. Initially such motivations were 
viewed in a primarily negative light. It was not until the Song that the autobiographical connection came to be valorized. In chapter 6, I consider an alternative position, that the Shiji was a "true record" and how the meaning of that term changed over time. I show how this aspect of Shiji interpretation reflected and influenced traditional Chinese attitudes toward history.

The third part explores textual issues. In chapter 7, I consider three problems related to Shiji authorship that go beyond Sima Qian: the question of Sima Tan, the work of Chu Shaosun, and the idea of a damaged Shiji text. In chapter 8, I discuss issues related to the authenticity of the "Letter in Reply to Ren An," which is often read as Sima Qian's finest autobiographical statement and a crucial interpretive key to the Shiji.

Kyong-McClain, Jeffrey. Ph.D., University of Illinois at Urbana-Champaign, 2009.

Excavating the Nation: Archaeology and Control of the Past and Present in Republican Sichuan. UnM: AAT 3392106.

This dissertation considers whether or not archaeology was an effective tool for nation-building elites in Republican China (1912-49), by looking at the discipline's fortunes in the off-center locale of Sichuan province. Through consideration of the multiplicity of agents and motives involved in archaeological enterprise in Republican Sichuan, Excavating the Nation shows that while nationalists believed the discipline held much propagandistic promise, in actual practice it failed to produce a coherent national narrative in the region.

The modern discipline of archaeology developed in China, as it had elsewhere in the world, in tandem with modern nationalism. Many intellectuals in Republican China hoped that archaeology would prove a useful tool in their efforts to construct a new national history, one that did away with myths and Imperial genealogies and in their stead produced a history of the triumphs of the Chinese nation as it spread from the Yellow River outward for five thousand years. Such a narrative, however, never could completely gain traction in Sichuan, which throughout the Republic remained only very weakly connected to China's political and academic heartland. Instead, archaeology in Sichuan grew in several disparate directions.

First, Protestant missionaries pioneered the discipline in Sichuan in the 1920 and 1930s, and while they made some inroads against antiquarian tradition, they were not themselves united over how best to interpret Sichuan's archaeological past, David Graham arguing for interpretations favorable to Chinese nationalism, but others defending understandings that placed their ethnically non-Chinese Christian converts more at the 
center of history. When Chinese archaeologists arrived in Sichuan en masse, during the War of Resistance against Japan (1937-45), it seemed that archaeology in Sichuan might yet be useful in telling national history. However, the archaeologists affiliated with the central government met one problem after another as Buddhist monks refused to be awed by "national treasures," the people resisted tomb excavation as a sacrilege, and local antiquarian Huang Xicheng defended the honor of Sichuan's native culture over that of the Central Plains. Finally, Chinese nationalism had its greatest success on the archaeological front in Sichuan in reinterpreting archaeological sites in ways favorable to finding ethnic Han presence in Sichuan's antiquity, particularly in transforming "Barbarian Caves" into "Han tombs," yet even here there was resistance. Ultimately, archaeological knowledge production in Republican Sichuan proved to be too unwieldy for Chinese nationalists, as it could not overcome diverse local opinion on Sichuan's past.

Leigh, Hoseok. Ph.D., California Institute of Integral Studies, 2010. The Philosophy of Non-Duality in "Zhaolun." UnM: AAT 3406176.

The purpose of this study is to examine Sengzhao's philosophy of nonduality in his Zhaolun. To meet the purpose, this study examines both Madhyamaka philosophy and the tradition from Lao-Zhuang to xuanxue as Sengzhao's philosophical backgrounds.

Throughout this study, the theories of both existent and inexistent substantial independent origination are criticized, and the reality of prajña is defined as sunyata identified with pratitya-samutpada. Sengzhao reveals the differences between the non-dualism within the nature by Zhuangzi and Guo Xiang and the non-dualism within pratitya-samutpada by Nagarjuna through Lao-Zhuang and xuanxue terminologies.

The result of this study indicates that the misunderstandings about Madhyamaka Buddhism of ge-i Buddhists who stand on the soil of xuanxue are caused by the misinterpretations of the unification between sunyata and pratitya-samutpada.

Li Chunlin. Ph.D., University of California, San Diego, 2010. Unity and Variety: A Study of the Chinese Language and its Cultural Implications. UnM: AAT 3408181.

Unity and Variety is a study of the relationship between language and culture in pre-modern China. Language here is understood as both speech and writing. In fact, the written form of Classical Chinese is the focus of the current project. The dissertation argues that there is a clear affinity between the Chinese language and diverse cultural expressions, including philosophy, literature, particular ways of theorization, histo- 
riography, etc. The Chinese written character and its consequences on the grammatical level have far-reaching influences on the perceptual modes and expressive strategies of ancient Chinese people. Therefore, an adequate understanding of the language, including the writing system, is essential for the proper understanding the culture. "Unity and Variety" in the title means through the single most essential feature of the language we may find the key to understanding a variety of cultural issues. The key I identify in this dissertation is xiang, or image, an idea systematically introduced in I Ching, the Book of Changes, and later embodied in the Chinese writing system.

The dissertation is divided into four chapters. Chapter One, "Introduction," propounds the thesis of the dissertation, defines key terms in the title, and discusses the scope, methodology, structure, and possible contributions of the dissertation. Chapter Two, titled "Xiang, Chinese Character, and Imaged Thought in Chinese Literature and Culture," is a systematic investigation of the idea of xiang, or image, its embodiment in the Chinese writing system, and its manifestations in various domains of Chinese culture. Chapter Three, titled "Syntax and Chinese Historiography: Reconsidering the Form of Shiji, Record of the Grand Historian, from a Linguistic Point of View," attempts to give an explanation for the unique form of Shiji, annals-biography, based on linguistic analyses. Chapter Four "Conclusion" summarizes the main points of the dissertation and points to possible directions for future research.

Lin Hsiu-Man. Ph.D., The University of New Mexico, 2009. The Biological Evidence of the San-Pau-Chi People and their Affinities. UnM: AAT 3359813.

Austronesian is one of the major language groups spoken. It is believed that Taiwan, Indonesian (east of Wallace line), or Bismarck Archipelago is the starting point for Austronesian migrations. It is also suggested that the prehistoric cultures of Taiwan were established by the ancestors of the modern Taiwanese indigenous populations, who are also Austronesian speakers. The goals of this project are to estimate biological relationships of the San-Pau-Chu (SPC) to other Asian populations (especially Polynesians) and to evaluate if Taiwan indeed plays a major role in the history of Austronesian migrations by using both dental morphological data (metric and nonmetric dental traits) and genetic evidence.

This dissertation is divided into six chapters. In chapter one, models of Austronesian dispersal are introduced. Additionally, hypotheses and significance of this study are emphasized. In chapter two, the linguistic, archaeological, osteological and genetic evidence for different models is reviewed. Chapter three provides a brief introduction to Taiwanese 
cultural history, and describes archaeological sites at the Tainan ScientificBased Industrial Park. In chapter four, a case study of dental variation from the SPC, Wu-Chien-Tsuo South (WCTS), and Nan-Kang-Li East (NKLE) sites are presented. In chapter five, genetic diversity and maternal ancestry in the SPC people is evaluated by using ancient DNA. Finally, in chapter six the biological evidence of the SPC people and their affinities is summarized.

This research is the first study in Taiwan trying to combine both morphological and genetic evidence to explore the biological nature of one prehistoric population. Because the dental morphological study and ancient DNA analyses seem to suggest a Northern Asian origin for the SPC people, it is proposed here that approximately $2,500 \mathrm{BP}$, some prehistoric Taiwanese came from mainland East Asia. However, the WCTS people, contemporaries of SPC, show a closer relatedness with the Namu from Hawai'i. Therefore, a multiple set of models must be considered. Studies with larger samples sizes and a wider range of archaeological sites in the future will also help to gain insights.

Luk Kei Yeung. Ph.D., Hong Kong University of Science and Technology (Hong Kong), 2009.

A Contemporary Interpretation of Laozi and Zhuangzi's Concepts of Dao and wuwei. UnM: AAT 3398652.

This thesis aims at discussing how to disclose and resolve the significance of the pervading paradoxical expression of Dao and wuwei throughout Laozi and Zhuangzi. According to the principle of coherence and the principle of charity, two eminent contemporary scholars' (Edward G. Slingerland and Chad Hansen) interpretations of Laozi and Zhuangzi will be investigated. Applying the theory of Conceptual Metaphor to Laozi and Zhuangzi's concept of wuwei, Slingerland argues that it manifests an irresoluble conceptual difficulty through the appearance of effort metaphors, which take their place uneasily alongside the dominant noeffort metaphors in the texts. By examining the meaning of wuwei in the texts, neither Laozi nor Zhuangzi suggests that it is obtained by the genuine effortlessness and unconsciousness of the agent. It is believed that such a paradox is produced by the inappropriate application of the Conceptual Metaphor theory to Laozi and Zhuangzi. In order to resolve the paradox of the ineffable Dao, Hansen, based on his investigation on the difference between the descriptive nature of English and the pragmative nature of Chinese language, interprets Laozi and Zhuangzi's dao as a prescriptive discourse rather than metaphysical object. According to Hansen's interpretation, Laozi, as a linguistic skeptic, acknowledges the conventionality and reversibility of discourse that cannot provide 
constant guidance in action, and advocates one cannot follow one codified guide in all situations. While Zhuangzi, by acknowledging all language is indexical, equalizes different discourses and puts them in a nonevaluative perspective. However, it is arguable whether Hansen's interpretations of Laozi and Zhuangzi cohere with the basic meaning of the texts. By analyzing the conceptual link between Dao and wuwei, a more cohesive interpretation between Laozi and Zhuangzi's philosophies will be provided. Furthermore, with the discussion of the relationship between Dao and wuwei, semantics and pragmatics' investigation in ancient China can also be revealed.

Lu Yimin. Ph.D., University of Toronto (Canada), 2009.

Talons and Fangs of the Eastern Han Warlords. UnM: AAT NR71363.

Warriors are a less visible topic in the study of imperial China. They did not write history, but they made new history by destroying the old. The fall of the first enduring Chinese empire, the Han, collides with the rise of its last warriors known as the "talons and fangs." Despite some classical or deceptive myths like the Chinese ideal of bloodless victories and a culture without soldiers, the talons and fangs of the Eastern Han warlords demonstrated the full potential of military prestige in a Confucian hierarchy, the bloodcurdling reality of dynastic rivalry, as well as a romantic tradition infatuated with individual heroism.

Lullo, Sheri A. Ph.D., University of Pittsburgh, 2009.

Toiletry Case Sets Across Life and Death in Early China (5th C. BCE-3rd c. CE). UnM: AAT 3400443 .

This dissertation is an exploration of the cultural biography of toiletry case sets in early China. It traces the multiple significances that toiletry items accrued as they moved from contexts of everyday life to those of ritualized death, and focuses on the Late Warring States Period (5th с. в.C.E.) through the Han Dynasty (206 в.C.E.-220 C.E.), when they first appeared in burials. Toiletry case sets are painted or inlaid lacquered boxes that were filled with a variety of tools for beautification, including combs, mirrors, cosmetic substances, tweezers, hairpins and a selection of personal items. Often overlooked as ordinary, non-ritual items placed in burials to comfort the deceased, these sets have received little scholarly attention beyond what they reveal about innovations in lacquer technologies. This dissertation presents a contextualized and nuanced understanding of toiletry case sets as enmeshed within rituals, both mundane and sacred. Chapter Two begins with their uses in life as items essential to fulfilling fluctuating social ideals of beauty and, as sets found 
in association with both females and males, tools through which gender identity was enacted rather than simply reflected. Chapters Three and Four focus on the layers of meaning that toiletries accrued when placed on display during the funerary rituals, arranged within organized tomb layouts, or kept aboveground for use in post-burial contexts. These chapters employ approaches to the material culture of death developed by Howard Williams, ideas that are themselves based on the classic sociological model for studying death rituals established by Robert Hertz. Such theories provide a framework for understanding how toiletry items may have affected the corpse, the soul, and the mourners differently. As items used in daily rituals of grooming and adornment, these sets became entangled within the biographies of individuals, ensured the order and beauty of the body into death, and may have acted as potent objects of memory throughout rituals surrounding death. This open inquiry of the toiletry case set demonstrates the potential for objects in early China to be understood as active within social, political and ritual contexts, and contributes to a growing discourse about the multiple meanings of objects.

Miao Jia Ming. Ph.D., University of Southern California, 2010.

A Comparative Study of Administrative Corruption in Ancient and Modern China. UnM: AAT 3434465.

The aim of this dissertation is to examine systemic corruption in relation to ancient and contemporary Chinese regimes in which corruption has been prevalent. The focus is on an examination of how corruption arises in regimes, how corruption has become systemic and entrenched in the Chinese society, and to what extent corruption helps and hurts the regime.

Most of the existing research either turns study of corruption in China into a blanket criticism of the regime, or tends to focus on officials' behaviors rather than the regime and the system, or to blame corruption on the Chinese culture without a careful analysis of to what extent culture conditions corruption and why the Chinese culture is what it is.

The author notices that corruption in contemporary China resembles, and to some extent revives and/or continues corrupt practices in China's imperial era, and that corruptions in both pre-modern and contemporary eras are systemic rather than individualized problems.

This study examines corruption in pre-modern and contemporary China through the goals of the regimes, the officialdoms, the corrupt practices, the ideological, institutional, and power structure of the regimes, and corruption's impact upon the goals of the regimes, especially their survival, stability, and security. Corruption in China should be studied as a systemic problem with reference to the regime's goals, 
basic power structure, and functioning. The author concludes that in a highly authoritarian society like China, corruption is closely related to the ideology and institutions chosen by the regimes to ensure the regimes' survival, security, and stability. Furthermore, while regimes struggle to keep corruption under control, nevertheless, corruption is often tolerated or utilized by the regimes to serve their purposes. Corruption is indeed a vice and has many negative impacts upon a given society, such as wasting public resources, corrupting public morality, sabotaging government procedures and policies, distorting justice, perpetuating inequality, fueling public discontent, undermining the legitimacy of a regime, and so on. There is no justification for corruption from a moral stand point. However, despite its inherent evilness, corruption, if observed from a functional perspective, has played a functional role in both the traditional and contemporary China with respect to the regimes' survival, security, and stability. It is in the process of understanding corruption's functional relation with the regime that we can better understand how corruption itself becomes systemic.

Miller, Bryan Kristopher. Ph.D., University of Pennsylvania, 2009. Power Politics in the Xiongnu Empire. Unm: AAT 3405356.

This thesis employs an integrated approach of the historical and archaeological evidence relevant to the study of the Xiongnu empire (3rd century B.C.E.-1st century C.E.) in an attempt to construct new contexts of understanding the political strategies for securing and ensuring power, legitimacy, and authority in the steppes. I have relied upon the full corpus of Chinese records which address the Xiongnu entity, synthesized the entirety of excavated materials in China, South Siberia, and Mongolia which relate to the Xiongnu phenomenon, and incorporated new survey and excavation data from two regions of the Xiongnu empire. Through the course of the dissertation, I utilize a paradigm of imperial strategies, rather than typologies of imperial polities, in order to provide a less restrictive manner of reconstructing the power politics of the steppe empire. A diachronic consideration of the combined textual narratives and archaeological materials exhibits two distinct periods of the Xiongnu polity. This dissertation focuses on the shifts between these two periods and the resulting new traditions that sought to distinguish and elevate restricted ranks of the imperial élite and assert a cosmopolitan culture and? steppe empire that together would ensure authority and control both within the empire and toward its neighbors. 
Moser, Jeffrey Christopher. Ph.D., Harvard University, 2010. Recasting Antiquity: Ancient Bronzes and Ritual Hermeneutics in the Song Dynasty. UnM: AAT 3435310.

This dissertation examines the ways in which the rediscovery of ancient bronzes in the eleventh century changed the ritual hermeneutics of the Northern Song dynasty. In particular, it considers the impact of bronzes on the interpretive strategies used to reconstruct the ceremonial paraphernalia - the vessels, vestments, and vehicles-named in the Book of Ceremony and Rites (Yili), the Rites of Zhou (Zhouli), and the Record of Rites (Liji). Because these classic texts had for centuries been esteemed as guidelines for appropriate imperial and aristocratic conduct, generations of exegetes had endeavored to determine the proper shape and substance of the implements named within. When eleventh century scholars began to decipher the inscriptions on ancient bronzes, they realized that many of them were actual remnants of the very ceremonies that these ritual classics purportedly recorded. Yet the bronzes looked quite different from ceremonial implements reconstructed by earlier exegetes. This discrepancy set off a crisis of confidence in the capacity of existing hermeneutics to reliably recover the normative models of antiquity. The present study explores some of the ways in which Northern Song emperors and literati dealt with that crisis.

By approaching the Song rediscovery of ancient bronzes as a catalyst for new intellectual problematics, this dissertation also draws into question modern attempts to collectively situate Song discourses on bronzes under rubrics such as antiquarianism or archaeology. These rubrics, I argue, are anachronistic, in that they suggest a coherent set of concerns and commonality of purpose that is not evidenced in the actual writings of the Song figures in question. By focusing on the arguments internal to the historical texts themselves, rather than the agendas of the later fields that adopted these texts as intellectual forebears, I attempt to narrate a more nuanced story of the various ways in which ancient bronzes informed Song intellectual life.

O'Grady, Caitlin Rose. Ph.D., The University of Arizona, 2009. Journeys of Our Ancestors: Conservation Science Approaches to the Analysis of Cultural Material. UnM: AAT 3387451.

The application and use of non-destructive portable x-ray fluorescence (XRF) analysis is a critical tool in the preservation and interpretation of cultural material. Portable XRF instrumentation produces elemental compositional data that is used to reconstruct current artifact composition, which can be related to materials and methods of manufacture, technological practice, as well as object condition and presence of corro- 
sion surfaces. Portable XRF analysis is used to assess a variety of material classes utilized in artifact manufacture. The dissertation research is based on a series of three case studies that represent typical groups of material culture commonly encountered in conservation and conservation science research.

Conservators and conservation scientists frequently undertake analysis and interpretation of disparate groups of materials. Often, these objects are tied together by research questions or themes directed by outside influences including preservation issues requiring action; curatorial research interests; museum exhibition programs; as well as many other cultural heritage stakeholders. To this end, both non-destructive and destructive tools that provide measurements of interest play critical roles in analysis. The case studies have been designed to answer common compositional questions relating to (a) bulk analysis of Chinese coins, (b) characterization of Southwestern ceramic colorants, and, (c) chemical examination of post-depositional manganese dioxide accretions occurring on archaeological ceramic materials. They evaluate the value of data produced using effectiveness of non-destructive portable $\mathrm{XRF}$ analysis for the interpretation of archaeological materials. The case studies provide a template for the development of conservation science research, predicated on object preservation, which produce meaningful data for the interpretation and conservation of the analyzed archaeological artifacts. Portable XRF provides useful data that is used to successfully interpret archaeological materials through (a) classification of metal alloys that can be related to published coin data, (b) identification of ceramic colorants and production technologies, and, (c) characterization of post-depositional product composition when used with established visual typologies.

O'Neill, Timothy Michael. Ph.D., University of Washington, 2010. Harbinger of Sequestered Intent: Language Theory and the Author in Traditional Chinese Discourse. UnM: AAT 3421883.

The dissertation begins by exploring specific issues in the history of Western philosophy, in particular the theory of language that underlies speculation about the possibility of ideographic writing. Starting with the China Illustrata of Athanasius Kircher, the first chapter proceeds to archaeo-historically excavate Kircher's language-theoretical sources and influences ultimately reaching all the way back to the intellectualhistorical origins of ideography in the texts of Aristotle and Plato. The second chapter examines traditional Chinese discussions of language (including the origin and function of writing), focusing on two ancient dictionaries: the Erya and the Shuowen jiezi. This chapter explains just 
how different pre-modern Chinese language theory is from Western ideographic speculation including the stark contrast between the Erya and such works as Peter Mark Roget's eponymous Thesaurus of English Words and Phrases. The vast difference between the two, simply stated, is that traditional Chinese theory requires quotidian human intent and concrete socio-historical embeddedness for linguistic meaning to function, whereas traditional Western theory requires reified, universal, transhistorical, perhaps even extraterrestrial Forms (eide, ideai) - what Derrida and others have called the "transcendental signifieds." The third chapter carries these language-theoretical issues to an examination of the work of the scribe Sima Qian (145-87 B.C.E.), who laid the cornerstone of author-theory in China. Forcibly castrated by the emperor for a crime he did not commit, consumed by humiliation and rage, Sima Qian proceeded to compile the monumental 130 chapter Records of the Scribe, one of the most sophisticated and politically provocative documents in the history of Chinese letters a text that ended up serving as the model for all subsequent historiography as well as biographical and autobiographical writing, prose fiction, and even much literary theory and criticism. The larger implication of the dissertation is that a better understanding of the differences in how the Chinese and Western traditions have discussed language, particularly how linguistic meaning functions, may well help to lead contemporary (posthumanist) theory to a more nuanced and culturally inclusive view of authorial intention.

Pitner, Mark Gerald. Ph.D., University of Washington, 2010.

Embodied Geographies of Han Dynasty China: Yang Xiong and his Reception. UnM: AAT 3445501

The dissertation constructs a detailed reception history for the controversial yet highly influential poet and thinker Yang Xiong (53 B.C.E.-18 C.E.) exposing to view the complex interplay between regional and imperial identity, the replicating relationship between biography and autobiography - between text and body, and the layered shifts in Ruist (Confucian) practices as these unfold over the changing intellectual and political landscape from the Han dynasty (206 в.с.E.-220 с.в.) to the Qing dynasty (1644-1911). This study traces the readership and interpretation of Yang Xiong's works and biography mapping the relationship between the history of a text and the history of the author. The first chapter explores the formative years of Yang Xiong reception and his move from mere scholar-recluse to sage, solidifying his place in the central tradition rather than the limited and regional. The second chapter explores the interplay between Yang Xiong's role as an astronomer and the increased readership of his Tai xuan jing in the context of developments in xuanxue. 
The third chapter focuses on the transitional period with the decline of xuanxue and the rise of new readership for Yang Xiong within the Guwen movement. The fourth chapter looks at the startling division in scholarly interpretation of Yang Xiong's works and actions in the Song dynasty (960-1279) and Yang Xiong's reestablishment on the regional landscape of his native Shu (in modern Sichuan). The final chapter outlines the developments that occurred after the Song and offers a broad set of conclusion for the whole of this study. Overall, this study reveals how changes in the understanding of the cosmos, the conception of human nature, Ruist practices, and the role of the sage blend in the reception history of Yang Xiong moving him across the geography of traditional elite society between the regional world of his native Shu and the imperial capital as his reception threads across the span of pre-modern Chinese intellectual history.

Salguero, C. Pierce. Ph.D., The Johns Hopkins University, 2010.

Buddhist Medicine in Medieval China: Disease, Healing, and the Body in Crosscultural Translation (Second to Eighth Centuries C.E.). UnM: AAT 3410115.

This dissertation is a study of the role of literary and cultural translation in the transmission and reception of Buddhist medicine in medieval China between the second and eighth centuries. This dissertation brings to light the diversity of medical material in the Chinese Tripitaka, analyzes the central metaphors and discourses in this corpus, and examines how these foreign medical ideas were understood in their historical context. I employ methodologies from Translation Studies to reconcile the study of the transregional exchange of linguistic and cultural repertoires with the agency of individual historical authors as they retooled and adapted foreign knowledge to forward contemporary social strategies. I utilize this theoretical framework to analyze how Indian medical doctrines influenced Chinese Buddhist discourses and practices, while also emphasizing the importance of disease, healing, and the body as sites of crosscultural negotiation.

Chapter 1 introduces the transmission of Buddhist medicine to China in the context of transregional currents of crosscultural religious and medical exchange. Chapter 2 outlines the theoretical approach of this dissertation, situating the translation of Buddhist medical doctrines within the context of indigenous Chinese cultural repertoires and the local religiomedical marketplace. Chapters 3 and 4 introduce the major metaphors at the foundation of Buddhist medical discourses, emphasizing the translation tactics and strategies mobilized in rendering these in the Chinese language. Chapter 5 focuses on the work of one sixth-century hagiographer, highlighting the role of healing narratives in the Buddhist 
proselytism. Chapter 6 looks at the strategies of cultural translation employed by authors of a range of indigenous Chinese Buddhist compositions between the sixth and eighth centuries, identifying connections between individual translators' treatments of Buddhist medicine and their social political, and personal contexts. A brief conclusion argues that a new approach prioritizing the role of translation in the dynamics of crosscultural exchange allows scholars to jettison the anachronistic categories of "religion" and "science" and move toward a greater appreciation of the integration of Buddhism and medicine in medieval China.

Sung Chia-fu. Ph.D., Harvard University, 2010.

Between Tortoise and Mirror: Historians and Historiography in EleventhCentury China. UnM: AAT 3415374.

This dissertation takes the conventional wisdom that Sima Guang's Zizhi tongjian (Comprehensive mirror to aid in government) was the most important and consequential achievement of eleventh-century Song historiography as the point of departure. A re-examination of the compiling history of the Comprehensive Mirror, however, reveals the intriguingly antithetical relationship Sima Guang held against the official historiography in general and the historical encyclopedia Cefu yuangui in particular. Chapter one proposes to view the official historiography as a mode of historiographical operation in the sense that it had its own place, procedure and product in the Song institutional and cultural context. Chapter two explores the historiographical significance of the Cefu yuangui as a continuing and creative development in the convention of official historiographical operation. The Cefu rewrote both the practically oriented leishu and the received Standard Histories into a taxonomical comprehensive history of lidai junchen shiji. Chapter three turns to the two "New" Histories by Ouyang Xiu. Both were rewritings based on the existing Standard Histories, and yet the stark contrast between one being consistently official and the other being intentionally kept non-official indicated Ouyang's ambivalent role of being both an insider and outsider in relation to the contemporary official historiographical operation. As a matter of interpretation, his "New" Histories were actually old to the extent that both went beyond the later examples of Standard Histories and reached back to the generic quintet of the great Han dynasty historian Sima Qian's Shiji. Chapter four excavates a hitherto rarely studied historical text $G u$ shi, whose intensive inter-textual relationship with the Shiji and other works by its author Su Che conspicuously embodies the ambiguities of the practice of "re(-)writing" in Song historiographical discourse. It is such a special kind of rewriting that I call it "over-writing." In the Conclusion I have come around to revisit Sima Guang's Comprehensive 
Mirror in light of the historiographical constellations construed by the preceding chapters. In terms of its (1) resistance to be conditioned by the place (and the culture associated with it) of Guange, (2) development of un-official procedures of efficient teamwork, and (3) textual product in the neither-categorical-nor-biographical format of critical chronology, the Comprehensive Mirror has presented itself as one of its own mode of historiographical operation in the eleventh-century Song China.

Sutherland, Heather B. Ph.D., University of Pennsylvania, 2009. Adaptation and Transmission in Early East Asian Funerary Arts: The Three Goguryeo Four Spirits Tombs in Ji'an, China. UnM: AAT 3405415.

The Donggou Four Spirits Tomb and Five Helmets Tombs 4 and 5 located in Ji'an, China are the subject of this dissertation. The tombs' structures and the main theme of their pictorial programs, the Four Spirits (the Green Dragon, the Red Bird, the White Tiger, the Dark Warrior, and, sometimes, the Yellow Dragon), identify them as belonging to the late Goguryeo Kingdom (37 в.C.E.-668 с.в.), one of the Korean Three Kingdoms. However, the interior decoration displays a multitude of regional variations making them unique among Goguryeo tombs with murals. Stylistically, the tomb paintings clearly belong to the sixth or early-seventh century. However, the main images and ideology the Ji'an murals represent can be traced to developments that occurred in Han China (202 в.C.E.-220 с.E.) and demonstrate an affinity for and deep understanding of ancient Chinese mythology and cosmology. This study attempts to identify and analyze the myriad images within the three Ji'an Four Spirits tombs.

This dissertation utilizes a variety of textual and visual sources. A combination of primary and secondary historical texts, both Korean and Chinese, are used to understand the period in which these tombs were created. Mythological and religious texts from the Zhou and Han periods of China are also important resources; concepts and creatures referred to in these texts permeated the funerary cultures of the later time periods, even on the Korean peninsula. In addition, funerary contracts and epitaphs as well as mirror inscriptions offer insight into the images found in the three Ji'an tombs. Mirrors are particularly important artifacts because, as portable objects, they demonstrate how images and concepts traveled to distant lands. Objects found in China, Korea, and Japan are evidence of the cultural interaction that the texts describe. Through these sources, many of the images within the three tombs can be identified. The imagery within the tombs can be interpreted as a symbolic recreation of the universe as well as aids for the deceased's ascension to the immortal realm. 
Van Auken, Newell Ann. Ph.D., University of Washington, 2006. A Formal Analysis of the "Chuenchiou" ("Spring and Autumn Classic"). UnM: AAT 3207826.

The Chuenchiou is a chronicle of events recorded in the state of Luu from 722 to 479 B.c.E., traditionally understood to employ subtle words to convey praise and blame. Chapter 1 explores the textual history of the Chuenchiou and provides a critical review of pertinent Western scholarship. Chapter 2 examines the use of date notations and Chapters 3 to 5 contain a formal categorical analysis of all records of the same type. Records were written in accord with regular rules that governed which types of events could be recorded and in what form. Records of the same type of event were recorded using similar format, and formal rules determined choice of main verb, style of reference to individuals, order in which states were listed in events involving multiple states, and degree of specificity of date notation. Exceptional records are uncommon, although attempts to explain irregularities have been the focus of much of the exegetical tradition associated with the Chuenchiou. The Tzuoo juann contains a set of passages, examined in Chapter 6, that comment directly on the Chuenchiou records. Like other commentarial traditions associated with the Chuenchiou, these passages attempt to explain deviations from the regular form, and provide an alternative to the traditional "praise and blame" interpretation of the Gongyang and Guuliang traditions. Some irregularities are attributed to lack of information and others to scribal error; elsewhere, the Tzuoo suggests that recordkeepers intentionally departed from the regular form to indicate that the event being recorded was itself exceptional, including events that were morally irregular, events that were in some respect ritually deficient, and those that were simply strange or unusual. In the concluding chapter, Chapter 7, I suggest that variations from the standard form may have sometimes been employed as a vehicle for implying value judgments that could not be indicated explicitly in the Chuenchiou records. To this study is appended a complete translation of the Chuenchiou and translations of the 154 direct commentary passages from the Tzuoo juann.

Wallace, Leslie. Ph.D., University of Pittsburgh, 2010.

Chasing the Beyond: Depictions of Hunting in Eastern Han Dynasty Tomb Reliefs (25-220 CE) from Shaanxi and Shanxi. UnM: AAT 3417447.

During the first and second centuries C.E. colonists living along the Northern Frontier of the Han Empire built tombs with stone doorways that depicted scenes of the hunt. These reliefs depict a fabulous world inhabited by mounted archers, hybrid xian (immortals) and frolicking/fleeing animals. Within these reliefs there is also a limited tendency to draw 
on the alternate lifestyles of the Xiongnu, a confederation of northern nomadic tribes who served as both neighbor and foe to the Han Chinese who lived in this area. Previous scholarship has seen hunting imagery in these reliefs as passive reflections of the mixed culture and economy of the region. I instead maintain that it was part of an iconographical program that depicted and facilitated the passage of the deceased to paradise across the dangerous borderlands between Heaven and Earth.

My dissertation argues that imagery in Shaanxi and Shanxi was actually a refinement of earlier Eastern Zhou (771-221 в.C.E.) and Western Han (206 в.с.в. -8 с.в.) depictions of the hunt and immortals, but that in this region, the positioning of the hunt at doorways created a liminal space representing the "Great Boundary" between this world and the next. This world is described in an inscription from a tomb excavated in Suide, Shaanxi that warns the deceased of the dangers that confront him if he does not return to the world of the living. On the basis of this inscription and similar "soul-summoning" passages from the Chu ci (Songs of the South) and Eastern Han dynasty tomb-quelling texts (zhenmu wen), I argue that hunting imagery in Shaanxi and Shanxi belongs to the desolate spaces that were believed to exist between this world and the next.

Furthermore, I conclude that these images were a local response adopted by the patrons because they lived in a militarized, colonized setting in which fears of foreign neighbors fused with their apprehensions of the 'beyond.'

Wang Suqi. Ph.D., The Chinese University of Hong Kong (Hong Kong), 2010.

Emergence of the Human Religious Icon in Early China: Xiwangmu Image During the Han Period (206B.C.-220A.D.). UnM: AAT 3446056.

Xiwangmu, the Queen Mother of the West, was the most important deity in early Chinese mythology, and the most prosperous period of Xiwangmu was the Han Dynasty. As a unique cultural phenomenon, the face of the Xiwangmu image went through different evaluation stages: first the mythical figure, then the dominator of the immortal land, and at last the human religious icon with popular worship in the whole empire, who had a long-term influence on later age. The Xiwangmu image was a key to understanding the ancient Chinese concept of images.

The first chapter is an introduction. Specifically, we first simply neaten the literature and pictures of Xiwangmu to present an overview. After that, the society background and the general beliefs in the Han Dynasty are given. At last, we introduce the research background of Xiwangmu and the research method of this thesis. 
Chapter II, III, IV and V, study Xiwangmu images in Henan Province, Jiangsu Shandong and Anhui Province, North of Shannxi and Northwest of Shanxi Province and Southwest China, respectively. In each of these Chapters, we first introduce the local elements in Xiwangmu images. After that, we conduct the typology study based on iconography. According to different materials and carriers, we establish the space-time framework and sequences of Xiwangmu images in each region, and sum up the characteristics of evolution.

In Chapter VI, we first summarize the templates of Xiwangmu images for all the areas, and further discuss the templates' variation and creation during their practice. After that, we conclude the image style of each area, as well as the communication and interaction among different areas. We also try to conjecture the method and route in which Xiwangmu Sages spread and circulated.

In Chapter VII, we first interpret Xiwangmu images' quality and function based on the image features, pictorial program, and relative positions. After that, we discuss Xiwangmu images' origin and development in the background of pre-Qin and Han Dynasty art and the external influence. The mutual stimulation and inner tension with Buddhist and Taoist images are also pointed out.

This thesis concentrates on Xiwangmu images on artwork and artifacts in the Han Dynasty. We analyze Xiwangmu's figure (including Dongwanggong), the image system, image structure and the pictorial program according to their different regions and materials. We further unearth the image meaning, significance and function. Through the case study of this subject, we make an attempt to find the inherent rules of ancient Chinese visual art, and we regard Xiwangmu Sage as the first human religious icon in early China.

Wiersema, Juliet B. Ph.D., University of Maryland, College Park, 2010. The Architectural Vessels of the Moche of Peru (C.E. 200-850): Architecture for the Afterlife. UnM: AAT 3409737.

This dissertation investigates sculpted representations of ritual architecture produced by the Moche (C.E. 200-850), a complex and sociallystratified society occupying Peru's north coast centuries before the formation of the Inca Empire. My study focuses on a single artifact type-the Moche architectural vessel-a portable fine ware ceramic container with a stirrup-shaped handle and straight spout which supports a miniature modeled building. Moche architectural vessels mimic the form of structures and features identified in full-scale Moche architecture. When discovered scientifically, these objects accompany elite burials found within or in close proximity to Moche ritual architecture, or huacas. For 
art historians and archaeologists, these portable artifacts constitute one of the most important sources of data on Moche ritual architecture and as such, permit us a more nuanced understanding of ancient ceremonial structures which have been compromised by centuries of erosion, treasure hunting, and cataclysmic events.

While Moche architectural vessels have been considered simple and somewhat generic representations of temples or temple complexes, my study suggests these objects instead relay explicit information about geographically, temporally, or ideologically specific ritual structures. In this dissertation, I propose a practical method for "decoding" these objects and demonstrate that, once deciphered, Moche architectural vessels can elucidate the original form, function, and ideological significance of Moche ceremonial architecture.

My research draws upon several disciplines including art history, anthropology, ethnography, and ethnomusicology. Important contributions include the assembly of the first Moche architectural vessel corpus (169 vessels), the creation of a detailed 1o-type Moche architectural vessel typology, a new method for visualizing these objects, and the discovery that several vessels are additionally acoustic artifacts.

My study presents a new investigative model, applicable to other areas in the ancient Andes and Mesoamerica, where, for millennia, ceramic representations of architecture formed an important part of burial ritual. Moche architectural vessels also engage in a cross-cultural dialogue with architectural representations made for burial by other ancient cultures around the globe, including Han Dynasty China, Middle Kingdom Egypt, Iron Age Italy, Ancient West Mexico, and Aztec Mexico. They also illuminate the rich potential of ceremonial objects made by advanced societies without text-based histories.

Wu Jui. Ph.D., University of Pittsburgh, 2010.

Mortuary Art in the Northern Zhou China (557-581 CE): Visualization of Class, Role, and Cultural Identity. UnM: AAT 3417428.

The period of Six Dynasties (221-581 C.E.) has traditionally been thought of as a time when "the Five Barbarians brought disorder to China." During this period, present-day Northern China was ruled by non-Han leaders, including the Xianbei, a pastoral people from China's northern frontier who founded the Northern Zhou Dynasty. In addition, Chinese historical texts from the Six Dynasties refer to "merchant barbarians" generally assumed to be Sogdians, who lived in oasis states in Central Asia in present-day Uzbekistan and came to China across the Silk Road. Most scholarship has assumed that the period of Northern Zhou ruled by non-Chinese leaders was "sinicized," and the adoption of Chinese 
features in burial and artifacts in foreigners' tombs is evidence of that acculturation process.

This dissertation, however, uses newly excavated materials from tombs dated to the Northern Zhou period, including the tombs of Xianbei leaders, Xianbei and Chinese generals, and Sogdian merchants, and proposes that visual arts and mortuary ritual played a role in creating and/or maintaining multiple sociopolitical and cultural identities for these residents of Northern Zhou. The theorization of power, agency, and cultural identity in recent publications has helped me analyze the processes involved in the construction of individual identity, group boundaries, and the interrelationships between socio-cultural groups. Theories of agency have helped me focus on choices made by different social and occupational groups.

This dissertation has explored how the patterns of use of mortuary objects documented multiple identities for these three classes listed above with specific ethnic backgrounds: the sovereigns who were Xianbei; the military class of Xianbei and Han-Chinese; and the merchant class of Sogdians. I have discussed how aspects of political, military, and merchant life in the Northern Zhou period created a setting that contributed to multiple roles and identities in each group. My study has demonstrated the construction of multiple identities among elites and how they consistently distinguished themselves from other members of society. This dissertation will be the first contextual analysis focused on the visualization of class, social roles and cultural affiliation by examining mortuary art in the Northern Zhou.

Yang Soon-Ja. Ph.D., University of Pennsylvania, 2010.

The Secular Foundation of Rulership: The Political Thought of Han Feizi (ca. 280-233 вс) and His Predecessors. UnM: AAT 3414191.

This dissertation examines the popular view of four thinkers in the Chinese Warring States period: Shen Dao, Shang Yang, Shen Buhai, and Han Feizi. They have been classified as Fajia. Specifically, Han Feizi has been known as a synthesizer of his predecessors on the basis of their three major tenets, Shang Yang's fa (written penal laws to regulate the people), Shen Buhai's shu (techniques to manipulate ministers), and Shen Dao's shi (power or authority). The first half part of this dissertation deals with three forerunners of Han Feizi in order to explore whether shi, shu, and $f a$ are the major tenets of Shen Dao, Shen Buhai, and Shang Yang respectively by analyzing overlooked sources such as fragments of their work. My examination shows that the conventional view has no solid textual basis. Shen Dao stresses the idea of $f a$ rather than shi; Shen Buhai discusses $f a$ instead of shu. In addition, I analyze Shang Yang's 
theory of $f a$ from the perspective of the relationship between law and utilitarianism, in which agriculture and war are the main tools to accelerate the interests of a state. In other words, $f a$ is the most critical issue in the view of these three thinkers; it means a standard of rewards and punishments, which thus can be rendered as "laws." The second part of this dissertation discusses Han Feizi's own thought and interprets him from a different perspective, not as a synthesizer of the Fajia group. His main concern is how a ruler controls powerful ministers and strengthens his authority by means of $f a$ along with $l i$ (ritual propriety). In the process, the term $f a$ in Han Feizi's work is used in two connotations: "laws" and "administrative regulations." That is, Han Feizi adopts the term $f a$ in the same way as his predecessors on the one hand, but expands it into a wide-ranging concept of sociopolitical regulation on the other. Han Feizi shares a concern with his predecessors, which is the establishment of a ruler-centered government by means of $f a$, but exposes himself to the vibrant intellectual environments of the Warring States period.

Yau Ka Man. Ph.D., The Chinese University of Hong Kong (Hong Kong), 2010.

Jades from the Tomb of Marquis Yi of Zeng: Characteristics of Jades from the Eastern Zhou Period and Their Relationship with the Middle Springs and Autumns Ritual Restructuring. UnM:AAT 3436616.

The focus and starting point of this study is a group of jades excavated from the tomb of the Marquis Yi of Zeng (died 430 в.с.Е.). This undisturbed tomb yielded nearly three hundreds pieces of jade; they were well preserved and were highly representative for their remarkable quality and workmanship.

Lothar von Falkenhausen proposed that a political movement occurred around 600 в.C.E., which resembled the Late Western Zhou Ritual Reform (circa 850 в.с.в.). He entitled this movement "the Middle Springs and

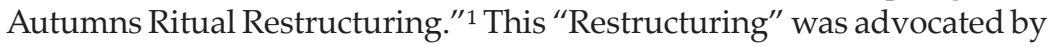
a group of rulers of local polities who wished to strengthen their newly established kingdoms and reinstate social order through the restoration of religious and ritual ceremonies of the Western Zhou period. The "Restructuring" was characterized by a shift of social hierarchy and a change in religious content which had significant impact on people's lives in Eastern Zhou society. The main intention of this research is to find out the characteristics of jades from the Eastern Zhou Period and their relationship with the "Restructuring".

1. Lothar von Falkenhausen, Chinese Society in the Age of Confucius (1000-250 BC): The Archaeological Evidence (Los Angeles: Cotsen Institute of Archaeology, University of California, 2006). 
This investigation proceeds from four major perspectives. The first section studies how the set of sumptuary rules in the ceremonial system established after the "Western Zhou Ritual Reform" have been restored by the ruling class after the "Restructuring." This research has revealed that a new ceremonial system has been established after the "Restructuring" to justify users' political and social status. The second section examines the changing roles of jade in everyday contexts after the "Restructuring," from the perspectives of its value, function, and significance in society. The research has shown that although the feudal system has collapsed gradually with rapid social mobilization, jades were mostly confined to the upper class during the entire Eastern Zhou period. Their marvelous craftsmanship and enormous size were used to display users' political power, extraordinary taste and wealth.

The third section will look at the issues surrounding the use and understanding of archaic jades during this period. The "Restructuring" advocated the restoration of religious cult and ritual of Late Western Zhou period, which led to the employment of archaic jade and motifs borrowed from bronzes as potent political symbol and legitimacy. The fourth section discusses the ways in which the emergence of new religious ideologies affected the manufacturing of jades for burial. The belief in the afterworld and the existence of soul affected the production of burial jades in terms of functions, form and style. These burial jades show that the religious transformation of the Qin and Han Dynasty in fact originated during the Warring States Period.

Furthermore, differentiation of jades used among different social classes is also considered throughout these discussions. Finally, this research concludes with the discussion of the discourse of the existence of regional differences of jade from the Eastern Zhou period; the outcome of the "Restructuring" and the characteristics of jade excavated from the Tomb of Marquis Yi of Zeng. This research is the only in-depth study of the Marquis Yi's jades known to date and should fill a major gap thirty years after their excavation. 